\title{
Correspondence
}

\section{The accuracy of Broselow pediatric emergency tape in estimating body weight of pediatric patients}

\section{To the Editor}

I have read with interest the study by ALSulaibikh et $\mathrm{al}^{1}$ on the accuracy of Broselow pediatric emergency tape (BPET) in estimating the body weight of pediatric patients. The authors mentioned that even though all the BPET estimated weight significantly correlated to actual weight, the body weight measurements ranging from 10 to $25 \mathrm{Kg}$ were best correlated, and were measured with a high degree of reliability. ${ }^{1}$ I presume that the implication of that finding in the clinical settings ought to be cautiously interpreted in the light of the following limitation. With the global pandemic of pediatric obesity, there are increasing concerns on the accuracy of BPET in estimating the weight of obese children. To my knowledge, the prevalence of pediatric overweight/obesity in the kingdom of Saudi Arabia is among the highest in the world (16.9\%). ${ }^{2}$ It was not obvious in ALSulaibikh et al's study ${ }^{1}$ the exact prevalence of obesity in the studied population. Hence, it would be a puzzling situation in employing BPET to estimate the weight of the critically ill obese Saudi children in the emergency departments who necessitate exact doses of resuscitative drugs and fixed sizes of instruments. I presume that the following 2 options might help unveil that puzzling state. 1) There is a need to develop an adjustment formula that could improve the BPET weight estimate in obese pediatric patients similar to that achieved in certain pediatric populations. ${ }^{3}$ 2) The pediatric advanced weight prediction in the emergency room (PAWPER) tape has been found to be statistically superior to BPET in the estimate of the weight of obese children ${ }^{4}$ and, hence, it might be considered a sound alternative to BPET.

Mahmood D. Al-Mendalawi Department of Paediatrics Al-Kindy College of Medicine University of Baghdad Baghdad, Iraq ORCID ID: orcid.org/0000-0003-2872-453X

\section{Reply from the Author}

No reply was received from the Author.

\section{References}

1. ALSulaibikh AH, Al-Ojyan FI, Al-Mulhim KN, Alotaibi TS, Alqurashi FO, Almoaibed LF, et al. The accuracy of Broselow pediatric emergency tape in estimating body weight of pediatric patients. Saudi Med J 2017; 38:798-803.

2. Al-Muhaimeed AA, Dandash K, Ismail MS, Saquib N. Prevalence and correlates of overweight status among Saudi school children. Ann Saudi Med 2015; 35: 275-281.

3. Tanner D, Negaard A, Huang R, Evans N, Hennes H. A prospective evaluation of the accuracy of weight estimation using the broselow tape in overweight and obese pediatric patients in the emergency department. Pediatr Emerg Care 2017; 33: 675-678.

4. Chavez H, Peterson RE, Lo K, Arel M. Weight estimation in an inner-city pediatric ED: the effect of obesity. Am J Emerg Med 2015; 33: 1364-1367. 